\title{
MERECIMENTO DE TUTELA NA SOCIEDADE DA INFORMAÇÃO: REEDIFICANDO AS FRONTEIRAS DO DIREITO CIVIL
}

\author{
Hian Silva Colaço ${ }^{1}$ \\ Francisco Luciano Lima Rodrigues ${ }^{2}$
}

\section{Resumo}

O direito à privacidade, em seu aspecto dinâmico, como direito à autodeterminação informativa, entrará em colisão com direito de acesso à informação, ocasião em que deve ser promovido um juízo valorativo com o intuito de aferir o interesse merecedor de tutela. O direito civil-constitucional vem apresentando-se como instrumento reedificante das fronteiras do direito civil, fortalecendo a proteção aos valores existenciais, assim, o juízo de merecimento de tutela coloca-se como uma instância positiva de legitimação dos atos privados à luz dos valores da ordem jurídica unitária. A metodologia utilizada é bibliográfica, jurisprudencial, pura, descritiva e exploratória. Concluiu-se que a correta aplicação do juízo de merecimento de tutela, quando da colisão entre o direito à privacidade e o direito à informação, no caso concreto, conferirá tutela preferencial ao direito à autodeterminação informativa, por melhor realizar os valores presentes na ordem jurídica como um todo, ao passo que é consentâneo à proteção do princípio jurídico da dignidade da pessoa humana.

Palavras chave: Sociedade da Informação. Direito Civil. Merecimento de Tutela. Direito à autodeterminação informativa. Direito à privacidade.

\section{INTRODUÇÃO}

A Sociedade da Informação (CASTELLS, 2005) revela um novo contexto, no qual se desenvolvem as relações sociais, marcado pela volatilidade e dinamicidade imanentes ao meio virtual, em que a grande riqueza e matéria-prima é a informação. A Internet apresenta-se como um espaço de natural liberdade para a construção, veiculação e transferência de informações, por isso, é inegável a necessidade de conferir proteção jurídica ao direito à informação, como forma de garantir o funcionamento das engrenagens das redes digitais de modo a gerar desenvolvimento econômico e social.

No entanto, em determinadas situações, o exercício do direito à informação pode não receber tutela preferencial, quando for capaz de esvaziar o núcleo essencial de outro direito ou interesse de igual valor para a

\footnotetext{
${ }^{1}$ Mestrando em Direito Constitucional nas Relações Privadas pela Universidade de Fortaleza-UNIFOR. Especialista em Direito e Processo Constitucionais pela UNIFOR. Membro do Grupo de Pesquisa em Direito Constitucional nas Relações Privadas. Email: hiancolaco@hotmail.com
} 
ordem jurídica: o direito à privacidade, visto, na sociedade da informação, sob uma feição dinâmica e positiva, como direito a construir livremente o espaço informacional e a esfera privada no meio virtual (RODOTÀ, 2008).

Diante da problemática evidenciada, percebeu-se que o direito civil, na sua feição tradicional, tendo como parâmetros o contrato e a propriedade, já não seria capaz de solucionar com eficácia os complexos litígios trazidos pela modernidade.

Dessa forma, a fisionomia do direito privado passou por inúmeras transformações, partindo do contexto histórico evidenciado com o surgimento do Estado Moderno e das ideias liberais - momento conhecido como "Era das Codificações"- até o fenômeno da constitucionalização do direito, o qual redimensionou toda dogmática do direito civil, ao deslocar as preocupações com a liberdade individual e o patrimônio para a dimensão solidarista - enquanto instrumento de promoção de valores - especialmente os existenciais.

Ao passo que as fronteiras do direito civil se remodelaram, o processo de interpretação da normativa civilística exigiu novos métodos compatíveis com a metodologia adotada. O método subsuntivo como técnica de interpretação e aplicação do direito civil apresentou-se insuficiente em face à complexa realidade histórica, econômica e social, fazendo surgir uma nova hermenêutica civil-constitucional, aliada à busca pela realização dos valores presentes na legalidade constitucional (PERLINGIERI, 2008).

Nesse sentido, o juízo valorativo dos atos particulares não se subsumi mais ao exercício de direitos subjetivos dentro dos limites legais, ou, ainda, ao controle negativo de ilicitude e não abusividade do ato, outrossim, passa-se a estabelecer um controle de legitimidade de todos os atos conforme a axiologia do sistema. Daí surge o conceito de merecimento de tutela, advindo do controle valorativo dos atos de autonomia (SOUZA, 2014, p. 76) e apresentando-se como importante instância de legitimação dos atos privados na perspectiva civilconstitucional.

Objetiva-se, portanto, a partir da instância de controle valorativo dos atos privados - também conhecida como merecimento de tutela - identificar balizas hábeis à solução da colisão entre interesses tuteláveis no contexto da sociedade da informação digital. Dentre tais interesses colidentes, destacam-se a pretensão de controle da circulação das informações pessoais, como consectário do direito à privacidade, e o interesse da coletividade em ter acesso livre às informações disponíveis no ambiente virtual.

Da ponderação entre os interesses igualmente tuteláveis pela ordem jurídica em abstrato, pode-se extrair os merecedores de tutela preferencial, a partir de uma análise de um caso concreto contido nas decisões proferidas pelo Superior Tribunal de Justiça, quando do julgamento do Resp 1.316 .92 e na apreciação da Reclamação nº 5.072/AC.

\footnotetext{
${ }^{2}$ Doutor em Direito pela UFPE. Professor titular do Programa de Pós-Graduação em Direito Mestrado/Doutorado da Universidade de Fortaleza. E-mail: lucianolima@unifor.br
} 
A metodologia utilizada na elaboração da pesquisa segue uma abordagem qualitativa, descritiva e exploratória, no que toca aos objetivos; bibliográfica quanto ao tipo; pura, quanto ao manejo dos resultados, colhidos a partir de um estudo descritivo-analítico, desenvolvido por meio de pesquisa teórica.

\section{AS TRANSFORMAÇÕES DO DIREITO CIVIL: DA "ERA DOS CÓDIGOS" A CONSTITUCIONALIZAÇÃO DO DIREITO CIVIL}

A delimitação das fronteiras do direito privado guarda íntima relação com os fatos históricos vivenciados, ao passo que as transformações do direito civil sofrem influência histórica, filosófica e política de cada período. Dessa forma, por opção metodológica, far-se-á uma análise das mudanças na fisionomia desse direito, partindo do contexto histórico evidenciado com o surgimento do Estado Moderno e das ideias liberais, momento conhecido como "Era das Codificações".

A Escola Pandectista Alemã propôs-se a adaptar os institutos tradicionais do direito civil romano à realidade do período oitocentista, ao elevar a propriedade privada e os contratos, espaços genuínos de expressão da autonomia da vontade, ao centro das preocupações do direito privado. Noutro momento, o advento do Estado Social e o fenômeno da constitucionalização do direito redimensionou toda dogmática do direito privado, ao deslocar as preocupações com a liberdade individual e o patrimônio para a dimensão solidarista do direito civil, enquanto instrumento de promoção de valores, especialmente os existenciais.

Dessa forma, ao passo que as fronteiras do direito civil se remodelaram, o processo de interpretação normativa do direito civil exigiu novos métodos comparativos com a metodologia adotada. O método subsuntivo como técnica de interpretação e aplicação do direito civil apresentou-se insuficiente em face à complexa realidade histórica, econômica e social, fazendo surgir uma nova hermenêutica civil-constitucional, aliada à busca pela realização dos valores presentes na legalidade constitucional (PERLINGIERI, 2008).

\section{Reconstruindo as fronteiras do direito civil: influxos históricos sobre a fisionomia do direito privado}

Suscita extrema controvérsia a tentativa de delimitar uma unidade conceitual capaz de permitir a compreensão das funções essenciais desempenhadas pelo direito civil de modo desconexo com as mudanças históricas ocorridas e seus impactos sobre a fisionomia desse direito (LOPES, 1955, p. 27). Dessa forma, as feições do direito civil e a definição de suas fronteiras melhor se explicam ao longo da história das instituições do que por meio da discriminação racional de seu conteúdo (MORAES, 2010, p. 4).

O declínio da Idade Média, com o esfacelamento do regime feudal, favoreceu ao desenvolvimento do comércio situado nos burgos e a ascensão da classe social burguesa. Tal evento histórico e social influenciou de 
modo decisivo nas relações jurídicas estabelecidas, afinal, o regime baseado unicamente na propriedade parcelada (domínio direito e útil), característico do feudalismo e marca fundamental da relação entre vassalos e senhor feudal, cedeu espaço para um novo modelo de relação jurídica - liberal-individual - concentrada na propriedade privada cujas raízes são extraídas do jusnaturalismo racionalista e da filosofia liberal (RODRIGUES, 2014, p. 566).

As Monarquias Absolutistas reinantes no início da Idade Moderna, após o declínio do regime feudal, caracterizadas pelo despotismo dos Reis e pela ausência de submissão do monarca à Lei, concentravam os privilégios em torno dos detentores de títulos da nobreza, excluindo os demais de direitos civis básicos, dentre eles a garantia da proteção da propriedade privada. Diante disso, a burguesia, que antes forneceu sustentação a tais regimes absolutistas, rebelou-se em face da concentração de riqueza e da ausência de liberdade individual.

Conquanto, a Revolução Francesa representou um marco histórico-temporal do surgimento do Estado Liberal Moderno, conferindo, nos termos da Declaração dos Direitos do Homem e do Cidadão de 1789, "quatro novos sentidos às relações jurídicas: liberdade, prosperidade, segurança e resistência à opressão" (RODRIGUES, 2014, p. 565).

No entanto, a cristalização dos ideais perseguidos pelos liberais deu-se somente com a sistematização do direito civil tradicional em torno do Código de Napoleão de 1804, que permitiu a distinção entre as leis civis, conteúdo principal do Code, e públicas, divisão esta utilizada como aparato ideológico das codificações do século XIX (DOMAT, 1825).

Os privatistas do Code Napoléon, assim como os adeptos da pandectista alemã, ancorados na revisitação de institutos do direito romano, pretendiam consolidar um esquema de ordenamento jurídico que passasse uma ideia de perenidade. O direito civil e as codificações, tidos como centro da ordem jurídica, eram dotadas de completude e, desse modo, constituíram-se numa fundamentação que se fez necessária para transpor os ideiais jusnaturalistas e alcançar o plano jurídico-positivo, consubstanciado na ideia do indivíduo sujeito de direito e dotado de "poder (potestà) da vontade" como o único motor do Direito Privado (GIORGIANNI, 1998, p. 39).

Embora concebendo-se o ordenamento jurídico do Direito Privado em função do indivíduo enquanto sujeito de direitos, não se reconhecia a pessoa como um fim em si mesmo e, portanto, dotada de dignidade, mas apenas como objeto de realização de interesses patrimoniais. Assim, o direito de ser homem continha "o direito que ninguém me impeça de ser homem, mas não o direito a que alguém me ajude a conservar a minha humanidade" (GIORGIANNI, 1998, p. 42).

Era enfática a tentativa de controle e supressão do poder estatal, de modo a se garantir o "reino da liberdade individual" (MORAES, 2010, p. 4), em torno do eixo central da propriedade individual, espaço no qual se exerce a plena autonomia do indivíduo, e do contrato, visto como meio de aquisição daquela. 
Com a promessa de garantir a estabilização das relações jurídicas envolvendo a propriedade e os contratos, tendo em vista a completude e a perenidade imanentes, encontrou-se, no "mundo dos códigos", o verdadeiro "mundo da segurança", no qual haveria certa previsibilidade quanto ao comportamento dos sujeitos ao estabelecerem suas relações jurídicas (IRTI, 1979, p. 16). Tal metodologia era sustentada por métodos hermenêuticos silogísticos de solução uniforme, baseada em fórmulas de direito prèt-à-porter, advinda da mera subsunção do texto legal ao fato.

Nesse contexto, fortaleceu-se a cisão entre Direito Público e Privado, este, na visão do jusnaturalismo racionalista, inserido no âmbito dos direitos naturais e inatos dos indivíduos e aquele emanado do Estado para a tutela de interesses gerais (GIORGIANNI, 1998, p. 38). Dessa forma, as codificações civis passaram a ser vistas como as "constituições do homem comum", ao passo que ocupavam as funções precípuas de disciplinar as instituições jurídicas de caráter privado e de erguer obstáculos às intromissões do Estado sobre os interesses dos indivíduos (GODINHO, 2015, on-line).

Desta feita, percebe-se que a summa divisio entre os dois ramos possuía um forte viés ideológicoeconômico, de modo a conduzir as relações jurídicas de direito privado ao primado da proteção do patrimônio em detrimento da pessoa, própria da visão individualista do direito no Estado Liberal (RODRIGUES, 2014, p. $567)$.

A ideia do Estado Liberal de "mão invisível" do mercado, cuja intenção primordial era de evitar ingerências estatais que colocassem em risco os valores da autonomia da esfera privada, da liberdade e da propriedade dos indivíduos (ANDRADE, 2001, p. 239), perdeu força, especialmente no início do século XX, diante das exigências sociais por uma maior atuação do Estado no sentido de concretizar determinados direitos que exigem prestações estatais.

Dessa maneira, com o advento do Estado Social, intervencionista e regulador, as fronteiras do direito civil precisaram ser remodeladas, de modo que a dimensão individualista, própria do período oitocentista, tornou-se incompatível com a realidade histórica, econômica e social vivenciada na Primeira Guerra Mundial e, especialmente, após a Crise de 1929, a qual fez ruir o modelo econômico liberalista.

As tradicionais estruturas do direito civil - contrato e propriedade - foram fortemente impactadas, assim como as formulações dogmáticas em torno do direito subjetivo e senhorio (poder) da vontade foram substituídas pela noção de interesse juridicamente protegido ou absorvidas pelo direito objetivo (MORAES, 2010, p. 7).

A supremacia do sistema fechado do direito privado personificado nos Códigos foi flexibilizada com o fenômeno da "descodificação", ocorrido na Alemanha, assim como no Brasil, também conhecido como autonomização de institutos do direito civil que passaram a ser regulamentados em leis especiais (WIEACKER, 2010, p. 628). 
Somado ao supracitado fenômeno, em razão da ruptura dos conceitos de completude e autossuficiência do direito privado, passou-se a falar em "crise do direito civil", ou declínio do direito privado, afinal, diante da profunda penetração do direito público sobre o direito privado, deu-se o rótulo de "publicização" do direito civil.

Contudo, é inapropriado falar-se de crise do direito privado, mas sim em crise na utilização de conceitos e métodos de interpretação ultrapassados, extraídos de uma realidade completamente díspar. O direito civil não perdeu espaço para o direito público, ainda que não se considere mais possível tal distinção - ao contrário - o direito privado ganhou novos territórios diante de suas tradicionais fronteiras (GIORGIANNI, 1998, p. 38).

Consequentemente, há de ser desconsiderada a distinção entre o direito público e privado, nos termos em que a doutrina tradicional impõe, conquanto, tal separação, cuja origem remonta o direito romano, não mais se traduz em face da realidade econômico-social vivenciada nem corresponde à lógica do sistema de direito atual (MORAES, 2010, p. 10).

O fenômeno do intervencionismo estatal conduziu a uma atuação legislativa na ordem do direito privado voltado à promoção de valores, principalmente concentrados em torno do princípio da igualdade substancial e da justiça distributiva. Nesse contexto, ganha força o fenômeno conhecido como constitucionalização do direito.

Reacendeu-se a necessidade de interpretar a própria normativa constitucional evolutivamente, adaptando-se aos valores éticos-políticos presentes no bojo da comunidade, de modo a representar as exigências de unidade do sistema e impedir a degeneração do Estado de direito formal. Diante disso, o princípio da legalidade constitucional impõe-se como um caminho obrigatório para o intérprete que pretenda reencontrar uma uniformidade de interpretação, utilizando as potencialidades implícitas no sistema jurídico (PERLINGIERI, 2008, p. 577).

Firmado o entendimento o qual as prescrições constitucionais possuem inegável caráter normativo, assim como são dotadas de supremacia; incontestável é o caráter precípuo das normas constitucionais na teoria das fontes do direito civil. Dessa forma, percebe-se que o direito constitucional foi realocado, deixando de ser repositório de meras expectativas políticas para servir como parâmetro interpretativo de todas as demais normas jurídicas, assim como incidir diretamente sobre as relações interprivadas.

Portanto, apresenta-se possível a aplicação direta das normas constitucionais, segundo fonte de disciplina das relações jurídicas intersubjetivas, haja vista os valores por elas expressos constituírem normas de comportamento idôneas a incidir sobre as situações subjetivas, de modo a funcionalizá-las aos valores do ordenamento unitário (PERLINGIERI, 2008, p. 590).

A revitalização dos institutos do direito privado e sua funcionalização aos valores presentes na legalidade constitucional, alvo de preocupação especialmente após o fim da Segunda Guerra Mundial, permitiu a construção 
de um direito civil mais humanizado e alinhado às questões de natureza extrapatrimonial.

Nesse contexto, diante das inúmeras atrocidades praticadas pelos regimes nazifascistas, reconheceu-se a necessidade de proteger enfaticamente o primado da dignidade da pessoa humana, deslocando o foco do direito civil em torno das relações patrimoniais para às existenciais, fenômeno este também conhecido como "despatrimonialização do direito privado" (MORAES, 2010, p. 12).

\section{Transformações dos parâmetros interpretativos do direito civil: da subsunção à hermenêutica civil-constitucional}

À medida que as fronteiras do direito civil se remodelaram, o processo de interpretação da normativa civilística exigiu novos métodos compatíveis com a dogmática adotada. Verificou-se insuficiente a adoção do método subsuntivo como técnica de interpretação e aplicação do direito civil, ao passo que uma nova hermenêutica civil-constitucional, aliada aos valores da ordem jurídica unitária, passou a guiar o intérprete na fundamentação das decisões judiciais.

Com o apogeu das codificações oitocentistas, no século XIX, era diminuto o papel dos textos constitucionais sobre as relações de direito privado, afinal, os Códigos eram dotados de completude e o processo legislativo possuía pretensão quase que exclusivista, pois não haveria abertura para o intérprete adotar outras fontes como parâmetro interpretativo. Forjou-se, portanto, um sistema fechado e autossuficiente, nos moldes da Escola da Exegese (TEPEDINO, 2001, p.3).

O direito codificado esgotava o fenômeno jurídico em todas as suas manifestações, admitindo-se tratar de um "fetichismo legal", ou melhor, "fetichismo dos Códigos", já que o traço marcante da exegética corresponde à admiração incondicional pela obra legislativa, uma confiança perpétua na suficiência da lei como única fonte de interpretação e aplicação do direito capaz de reger todas as formas de relação da vida social (BOBBIO, 1993, p. 242).

Nesse passo, a dogmática adotada justificava-se como reação às arbitrariedades praticadas pelos monarcas absolutistas, os quais desprezavam o texto legislativo e decidiam conforme suas pretensões pessoais. Portanto, a adoção da técnica puramente silogística-matemática de interpretação e aplicação do direito civil visava reduzir ao máximo o subjetivismo do intérprete, fazendo valer a completude dos códigos e a segurança na previsibilidade e estabilidade das decisões judiciais.

Em formulação clássica, o método subsuntivo adotado restringia o intérprete a uma atuação puramente mecânica de encaixe da premissa maior (norma) sobre a menor (fato). Contudo, tal procedimento silogístico não era capaz de conferir corretas soluções a todos os problemas da vida social, pois, ao estabelecer como premissa maior apenas o texto legal, desconsiderava que toda lei carece de interpretação, assim como nem toda proposição 
normativa está contida claramente na letra da lei (LARENZ, 2012, p. 383).

Tal técnica impedia o intérprete de buscar qualquer recurso a elementos estranhos ao texto legislativo no momento da interpretação-aplicação do direito. Somente seriam legítimos comportamentos formalísticos, já que o sentido do texto estaria hermeticamente presente nele mesmo (PERLINGIERI, 2008, p. 601). A referida dogmática do direito civil orientava-se pelo brocardo segundo o qual in claris non fit interpretatio, ou seja, diante da clareza do texto legal, desnecessária a sua interpretação, bastando a aplicação literal do enunciado normativo ao fato.

Entretanto, com a apresentação das novas fronteiras do direito civil pela metodologia civil-constitucional, o referido brocardo foi colocado em xeque, ao verificar-se que nenhum caso será de fato "claro". Outrossim, partindo da premissa pela qual só existe direito à luz do caso concreto - o "ordenamento vigente é o conjunto dos ordenamentos dos casos concretos" e "vive, portanto, exclusivamente enquanto individualizado e aplicado aos fatos" (PERLINGIERI, 2008, p. 201) - conclui-se por inadequada a busca por uma norma abstrata aplicável ao fato de forma subsuntiva.

Somente após ter consciência da integralidade do sistema jurídico, contido pela plasticidade de normas dentre as quais se destacam as constitucionais, o intérprete poderá extrair a normativa aplicável, ao passo que o ordenamento apenas se completa com a fusão de seus elementos ao caso concreto. Dessa maneira, "nenhuma hipótese de aplicação do direito dispensa o processo interpretativo" (SOUZA, 2014, p. 80).

A adoção da tradição hermenêutica em torno da suposta neutralidade silogística propunha a ideia de segurança jurídica com a uniformidade das decisões judiciais. Entretanto, a intenção fora subvertida, pois tal método permitiu ao intérprete transvestir e justificar suas pré-compreensões, escolhas pessoais e políticas sobre a forma de determinados enunciados normativos irrefutáveis, já que a fundamentação adotada era imune segundo os padrões hermenêuticos utilizados. O positivismo acaba por beirar a discricionariedade, ao se delegar aos intérpretes a resolução de casos difíceis não amparados diretamente por textos legais (STRECK, 2009, p. 69).

Noutra perspectiva, a utilização das técnicas da hermenêutica civil-constitucional, pautadas na necessidade de fundamentação das decisões judiciais à luz dos valores da ordem jurídica, colocou-se como solução adequada a sanar as consequências do ambiente de incertezas e inseguranças (DENNINGER, 1993, p. 368), próprios do período vivenciado atualmente. A moldura normativa acessível ao intérprete é alargada para toda a axiologia do sistema, cabendo-lhe fundamentar a decisão sobre os influxos da legalidade constitucional.

Aplicar a norma e interpretá-la deve corresponder a um "momento único", ao passo que, o ato de interpretar não se subsume ao aspecto estático de aplicar no caso concreto a norma que melhor se enquadra, mas encontrar a solução a qual melhor se coadune com a ordem jurídica e seus valores vistos de forma global (SOUZA, 2014, p. 79). 
A introdução da legalidade constitucional como parâmetro interpretativo das normas do direito civil elevou à centralidade a presença de normas-princípios a balizar a solução de controvérsias, a fim de se adotar critérios de interpretação sistemática e axiológica. Conforme destacou-se, a norma clara ou não deve ser interpretada, consoante aos princípios e aos valores do ordenamento, e deve resultar de um processo argumentativo não somente lógico; no entanto, axiologicamente de acordo com as escolhas de fundo do ordenamento, o qual permite a penetração de valores e princípios historicamente caracterizados (PERLINGIERI, 2008, p. 595).

Dessa forma, evidenciou-se que, muitas vezes, haverá interesses igualmente tuteláveis por normas jurídicas capazes de oferecer soluções colidentes. Assim, a técnica da ponderação entre princípios apresenta-se como solução ao intérprete, quando diante de dois exercícios particulares em rota de colisão igualmente fundamentados por valores do sistema.

Ao distinguir normas-regra e normas-princípio, afirma-se que as primeiras correspondem a enunciados normativos de textura menos aberta, por isso, o eventual conflito entre tais normas seria resolvido pelo critério do tudo-ou-nada (DWORKIN, 2010), pelo campo da validade ou diante da eventual existência de uma cláusula de exceção(ALEXY, 2008).

Contudo, as normas-princípio podem ser consideradas como mandados de otimização, havendo colisão entre estas, caberia ao intérprete realizar a devida ponderação, por meio da técnica de sopesamento, de modo que uma deva ceder espaço para outra no determinado caso concreto, mediante a chamada lei de colisão (ALEXY, 2008). Acrescenta-se que a prevalência de um princípio em relação a outro, em determinada situação, não representa a exclusão deste do sistema jurídico ou o seu comprometimento na dimensão de peso (DWORKIN, 2010).

Diante de tais considerações conceituais, a ponderação passou a ser adotada como técnica de solução dos hard cases, conhecidos como casos de difícil solução em razão da aplicação de princípios em rota de colisão. Todavia, na esteira da metodologia civil-constitucional, importa destacar a inexistência de casos fáceis ou de clara elucidação, pois, cabe ao intérprete, na atividade una de aplicar e interpretar o direito, realizar sempre a legalidade constitucional (PERLINGIERI, 2008, p. 589).

Conquanto, "afirmar a unidade e a coerência de um ordenamento complexo implica um esforço diuturno (e não esporádico) de compatibilização das normas que o compõe" (SOUZA, 2014, p. 87). Nesse sentido, diante do caso concreto, cabe ao hermeneuta buscar a harmonização dos inúmeros valores, princípios e regras presentes no sistema, os quais, muitas vezes, são potencialmente conflitantes. $\mathrm{O}$ intérprete deve ponderar constantemente, pois não há ordem hierárquica predefinida entre todos os bens e valores jurídicos em abstrato (LARENZ, 2012, p. 575). 
O relato acerca da predominância de uma ambiente de incertezas não corresponde necessariamente à conclusão equivocada dos críticos à perspectiva civil-constitucional os quais afirmam que o atual mecanismo de interpretação-aplicação do direito não oferece segurança jurídica, estabilidade e previsibilidade das decisões judiciais.

O resultado é exatamente oposto, afinal, em razão da segurança jurídica decorrer da coerência lógica e harmônica das instituições da ordem jurídica democrática, o sistema hermenêutico proposto pelo direito civilconstitucional é muito mais racional e coeso, se comparado ao adotado pelo positivismo jurídico.

Assim, ao exigir do intérprete uma fundamentação jurídica embasada nos valores do ordenamento jurídico visto como um todo, reduz-se consideravelmente a subjetividade desse na aplicação de enunciados normativos, de modo a oferecer muito mais estabilidade e segurança jurídica ao sistema (MORAES, 2010, IV).

\section{MERECIMENTO DE TUTELA COMO INSTÂNCIA POSITIVA DO CONTROLE VALORATIVO DOS ATOS PRIVADOS}

Revisitados os fatos históricos os quais influenciaram diretamente as transformações do direito civil, partindo do período das codificações oitocentistas à consolidação da metodologia do direito civil-constitucional, percebeu-se que o controle da autonomia privada foi diferentemente realizado em cada fase respectiva.

O juízo valorativo dos atos particulares não se subsume mais ao exercício de direitos subjetivos dentro dos limites legais, ou, ainda, ao controle negativo de ilicitude e não abusividade do ato, outrossim, passa-se a estabelecer um controle de legitimidade de todos os atos conforme a axiologia do sistema. Daí surge o conceito de merecimento de tutela, advindo do controle valorativo dos atos de autonomia (SOUZA, 2014, p. 76) e apresentando-se como importante instância de legitimação dos atos privados na perspectiva civil-constitucional.

\section{Consagração do juízo de merecimento de tutela: nova instância de valoração dos atos na perspectiva civil-constitucional}

Os influxos históricos foram decisivos na redefinição das fronteiras da legalidade no direito civil, influenciaram a dogmática metodológica do direito privado e traçaram a evolução das técnicas de interpretaçãoaplicação desse direito. Desta feita, ao longo dessa trajetória, uma questão jurídica sempre caminhou no eixo central das discussões: qual seria a dimensão de controle da autonomia privada.

Por volta dos séculos XVII e XIX, a legalidade do direito civil era balizada pela obediência à lei em sentido estrito, ao passo que o principal objetivo era impedir a ingerência estatal no espaço da autonomia privada, que era quase ilimitada, possuindo como único obstáculo a ilicitude.

Os Códigos tutelavam uma única forma de relação jurídica decorrente da autonomia da vontade: os vol.10, no. 02, Rio de Janeiro, 2017.pp. 1125-1145 
direitos subjetivos. Tais direitos delimitavam os amplos domínios do senhorio da vontade, a "atribuir-se à vontade individual um domínio dentro do qual ela reina independentemente de qualquer vontade estranha" (HABERMAS, 1997, p. 84).

Posteriormente, identificou-se que determinadas condutas, estruturalmente lícitas, seriam capazes de contrariar o espírito do direito, por ocasião do seu exercício, desenvolvendo-se, assim, uma nova modalidade de controle valorativo da autonomia da vontade conhecida como abuso de direito (JOSSERAND, 1927).

A teoria do abuso de direito trouxe um novo enfoque para o juízo valorativo dos atos privados, em uma perspectiva mais dinâmica, passou-se a aferir se determinados atos formalmente lícitos eram capazes de contrariar o fundamento axiológico-normativo da norma jurídica no momento de seu exercício. Vale dizer, "o titular do direito subjetivo viola limites intrínsecos da norma que são: a finalidade social, econômica, a boa-fé e os bons costumes" (CALCINI, 2004, p. 38).

Diante disso, estabeleceu-se um controle de legalidade dos atos predominantemente negativo fundado no juízo de licitude e não abusividade. No entanto, tal sistema tornou-se insuficiente frente aos novos paradigmas introduzidos pelo pensamento jurídico, especialmente com o advento do Estado Social, momento o qual o direito passou a assumir uma importante função de promoção de valores e não somente a de repressão de condutas.

A perspectiva civil-constitucional introduziu um novo parâmetro de legitimação dos atos de autonomia, baseado na medida de realização da legalidade constitucional. Dessa forma, diante do caso concreto, determinados atos lícitos e não abusivos podem não ser tão merecedores de tutela quando colidirem com outras situações jurídicas que melhor realizem os valores juridicamente relevantes.

Destarte, o intérprete ordinário deve guiar a interpretação à luz dos valores presentes na legalidade constitucional; assim, a qualificação dos institutos jurídicos, regulados e previstos por leis ordinárias, deve-se realizar mediante a adequação aos princípios e valores constitucionais, de modo que seja sopesado o merecimento de tutela (PERLINGIERI, 2008, p. 582).

O fortalecimento da ideia de função promocional do direito ensejou a adoção de sanções positivas, consubstanciadas em incentivos ou tutelas prioritárias aos atos que melhor realizem os valores da ordem jurídica. Por essa razão, revela-se o merecimento de tutela como uma instância positiva de controle dos atos privados (SOUZA, 2014, p. 95).

Ressalta-se que essa instância positiva de controle valorativo dos atos particulares se apresenta como instrumento hermenêutico hábil a solucionar os chamados hard cases, os quais reputam-se difíceis não porque necessariamente envolvem colisões entre princípios, mas porque somente o recurso à axiologia do sistema jurídico permite alcançar uma resposta definitiva à controvérsia.

Nesse contexto, o controle do merecimento de tutela será feito diante do caso concreto; bem como o ato 
merecedor da tutela preferencial será sempre em termos relativos, pois o ato o qual teve de ceder - em razão do exercício particular que foi capaz de promover os valores da totalidade do sistema com maior ênfase -

abstratamente apresenta-se plenamente conforme os valores da ordem jurídica (SOUZA, 2014, p. 95).

A aferição do interesse merecedor de tutela, diante do exercício colidente de atos lícitos e não abusivos igualmente conformes os valores do sistema, será guiada pela identificação do ato que melhor realize o princípio da legalidade constitucional, por meio de um controle de mérito inspirado nas ideias de razoabilidade, proporcionalidade e adequação (PERLINGIERI, 2008, p. 184).

Identifica-se entre duas ou mais pretensões tuteláveis a solução a ser extraída da aplicação unitária do sistema, de modo a prevalecer o interesse mais consentâneo com a axiologia, capaz de promover harmonicamente e de forma mais adequada os valores juridicamente relevantes. Dessa forma, tal controle valorativo estimula o exercício dos direitos em uma perspectiva solidarista, pois se oferece tutela preferencial ao interesse capaz de melhor promover os valores da ordem jurídica.

Qual seria a baliza segura a orientar o intérprete quando da valoração entre o interesse que melhor fosse capaz de realizar a legalidade constitucional? Ao conceber-se a dignidade da pessoa humana enquanto princípio jurídico orientador e unificador de toda ordem jurídica, fundamento do Estado Democrático de Direito e da República Federativa do Brasil, valor fundamental a justificar o fundamento jurídico-normativo dos direitos fundamentais (BARROSO, 2012, p. 64), percebe-se que o interesse merecedor da tutela prioritária será o mais consentâneo com a proteção e promoção da dignidade da pessoa humana.

\section{Conteúdo jurídico da Dignidade da Pessoa Humana como baliza para a identificação do interesse merecedor de tutela}

Diante da reconstrução do sistema de direito privado e da revitalização de suas bases metodológicas, apresentam-se as normas constitucionais no ápice do sistema jurídico e as normas diretivas ou normas-princípio como instrumentos de veiculação dos valores da ordem jurídica (PERLINGIERI, 2007, p. 35).

Nesse sentido, a busca por um compromisso aceitável entre os valores fundamentais comuns e os espaços da liberdade, de modo a permitir a correta valoração dos atos particulares e das escolhas na condução da vida privada, apresenta-se como um desafio do direito civil-constitucional (MORAES, 2010, p. 75).

A partir daí insurge a importância da dignidade da pessoa humana, enquanto princípio jurídico, como bússola hermenêutica hábil a fornecer ao intérprete a direção adequada à solução mais consentânea aos valores da ordem jurídica. Portanto, o princípio da dignidade da pessoa humana impõe-se como baliza na identificação do interesse merecedor de tutela, especialmente nas decisões envolvendo os casos difíceis, quando não existem soluções claras e acabadas no direito positivo. 
Visto na sua dimensão externa, enquanto promotora de direitos, aspirações e responsabilidades, a dignidade humana ascendeu como um conceito jurídico. Tal fato gerou inúmeras mudanças no pensamento jurídico, pois fez ruir a crença no formalismo e no raciocínio puramente dedutivo (BARROSO, 2012, p. 62), dando lugar à fundamentação das decisões judiciais conforme a legalidade constitucional (PERLINGIERI, 2008), de modo a funcionalizar a aplicação dos institutos do direito civil.

Podem ser extraídas do significado essencial de dignidade duas funções: a dignidade enquanto fonte de direitos e deveres e a dignidade como instrumento interpretativo integrante do núcleo essencial dos direitos fundamentais. Nesta função, afirma-se que ela informa a interpretação-aplicação dos direitos fundamentais em tensão e auxilia a definição dos limites de cada direito no caso concreto, por isso não pode ser considerada como um "direito em si", mas como alicerce último e substrato material de todos os direitos verdadeiramente fundamentais (BARROSO, 2012, p. 66).

Conquanto, tal princípio encontra seu substrato material em quatro postulados, de modo a ser subdividido nos corolários da igualdade, integridade psicofísica, liberdade e solidariedade. Tal decomposição permite demonstrar que, no plano fático, tais corolários comumente podem colidir entre si, representando pretensões ou interesses merecedores de tutela. Dessa maneira, o "fiel da balança, a medida da ponderação, o objetivo a ser alcançado, já está determinado, a priori, em favor do conceito da dignidade humana" (MORAES, 2008, p. 85).

Finalmente, conclui-se que a dignidade da pessoa humana, como princípio jurídico capaz de reconhecer valor intrínseco a todo homem - impedindo-o de ser tratado como mero objeto para a realização de determinados fins (KANT, 2007) - impõe-se como eficaz baliza a auxiliar o intérprete na identificação dos interesses merecedores de tutela.

\section{JUÍZO DE MERECIMENTO DE TUTELA DOS ATOS PRATICADOS NO CONTEXTO DA SOCIEDADE DA INFORMAÇÃO}

A nova morfologia social e a estrutura dominante na sociedade da informação digital organiza-se por meio das "redes". Assim, fala-se que "a difusão da lógica de redes modifica de forma substancial a operação e os resultados dos processos produtivos e de experiência, poder e cultura" (CASTELLS, 2005, p.573).

Diante da impossibilidade de se exercer controle sobre as consequências da tecnologia em suas mais amplas dimensões espaço-temporais, em meio a um ambiente de incertezas e inseguranças (DENNINGER, 1993, p. 368), faz-se imprescindível fazer um juízo valorativo dos atos particulares praticados no contexto da Sociedade da Informação.

Apresentar-se-á, dessa maneira, os interesses colidentes no meio digital, dentre os quais se destacam a 
pretensão de controle da circulação das informações pessoais, como consectário do direito à privacidade, e o interesse da coletividade em ter acesso livre às informações disponíveis no ambiente virtual. Da ponderação entre os interesses colidentes, extrair-se-á os merecedores de tutela preferencial, utilizando como parâmetro a análise crítica das decisões do STJ no Resp1.316.92 e na Reclamação no 5.072/AC.

\section{A Revolução da Tecnologia da Informação e sua interface com o Direito}

O final do século XX e início do século XXI representam um intervalo na história, cuja característica principal corresponde à transformação da "cultura material", com o surgimento de um novo paradigma tecnológico exteriorizado na chamada Revolução da Tecnologia da Informação.

Assim como a máquina à vapor e a eletricidade apresentaram-se como combustível das Revoluções Industriais, as tecnologias da informação, processamento e comunicação representam a principal fonte de energia da revolução em análise. O processo de transformação tecnológica expande-se conforme a capacidade de gerar, armazenar, recuperar, processar e transmitir as informações, por isso, afirma-se que o mundo tornou-se digital (NEGROPONTE, 1995).

O advento da "Sociedade da Informação" (CASTELLS, 2005) acelerou a dinâmica das relações sociais e, consequentemente, redimensionou a natureza das relações jurídicas, as quais ganharam notória volatilidade em razão do meio virtual. O ambiente foi transformado de modo tão radical, levando as próprias pessoas a se modificarem, com o desiderato de adaptar-se às mudanças (WIENER, 1973).

Edifica-se uma sociedade de modo panoptizado, esgarçando os limites entre os interesses privados e a "arena pública" e construída de modo a suprimir o conceito físico de espaço, visto que a modernidade se desenvolve de modo liquefeito, pronta a se adaptar a qualquer realidade (BAUMAN, 2013).

Em virtude da insaciável sede de informação e da possibilidade de armazenamento perene das informações, a tecnologia digital constitui instrumento de elevada valia para uma sociedade de extrema vigilância (RODOTÀ, 2008), na qual o direito mais precioso passa a ser a capacidade de controlar o fluxo das informações pessoais. Afinal, "quem controla o passado dirige o futuro, quem dirige o futuro controla o passado" (ORWELL, on-line, 2015).

Dessa maneira, embora apresente-se como espaço genuíno da liberdade, o ambiente digital deve ser tutelado pelo Direito, pois é um meio propício à violação de interesses juridicamente protegidos. Por isso, relevante se mostra o controle valorativo dos atos praticados nesse universo, à luz dos valores presentes na ordem jurídica.

Os interesses merecedores de tutela no contexto das relações virtuais: entre o direito à 


\section{informação e à privacidade}

O tecido social das relações desenvolvidas no meio virtual comporta, sem excluir demais direitos ou interesses juridicamente protegidos, necessariamente, o exercício do direito à informação e consequentemente do direito à privacidade. Aquele decorre da textura da própria morfologia das redes arquitetadas no ambiente digital, afinal, a construção, veiculação e transferência de informações constituem-se como propósitos e funções essenciais ao funcionamento da estrutura virtual.

A grande riqueza e matéria-prima da Revolução na Sociedade da Informação corresponde, silogisticamente, ao poder sobre a circulação dessas informações. Inegável que esse interesse tutelável pela ordem jurídica necessita de especial proteção no ambiente virtual, pois, diante de eventual cerceamento de seu exercício, faz-se parar as engrenagens da rede, gerando consequências negativas a toda ordem social e econômica.

Entretanto, em determinadas situações, o exercício do direito à informação pode não receber tutela preferencial, quando for capaz de esvaziar o núcleo essencial de outro direito ou interesse de igual valor para a ordem jurídica: o direito à privacidade. Importa salientar que este direito humano, fundamental e de personalidade não pode mais ser visto apenas como "direito de ser deixado só" (WARREN; BRANDEIS, 1890, p. 193) ou corresponder à esfera de proteção restrita à intimidade.

Diante das experiências complexas da sociedade informacional, passa-se a tutelar a privacidade do sujeito em uma perspectiva mais dinâmica, inclusive, para the garantir o controle das informações pessoais que circulam a seu respeito e de autodeterminar a construção da sua vida privada (RODOTÀ, 2008, p. 17).

Dessa forma, percebe-se que, diante de conflitos envolvendo interesses juridicamente relevantes no âmbito das relações virtuais, a instância de controle valorativo dos atos privados deverá agir a fim de identificar o interesse merecedor de tutela preferencial em cada caso concreto, ou seja, se o direito à privacidade deverá ceder perante o direito à informação ou não.

Uma das decisões mais polêmicas envolvendo a aplicação do merecimento de tutela na sociedade da informação refere-se à ação promovida pela apresentadora Xuxa Meneguel em face da Google Inc., com o desiderato de compelir este provedor de busca a remover os resultados relativos à expressão "xuxa pedófila" ou, ainda, qualquer outro padrão de busca que relacionasse o nome da apresentadora a uma prática criminosa qualquer. Observa-se o juízo de valoração promovido pelo STJ na decisão em análise:

Não se pode, sob o pretexto de dificultar a propagação de conteúdo ilícito ou ofensivo na web, reprimir o direito da coletividade à informação. Sopesados os direitos envolvidos e o risco potencial de violação de cada um deles, o fiel da balança deve pender para a garantia da liberdade de informação assegurada pelo art. $220, \S 1^{\circ}$, da $\mathrm{CF} / 88$, sobretudo considerando que a Internet representa, hoje, importante veículo de comunicação social de massa [...]. 9. Recurso especial provido. (BRASIL, 2013).

A Terceira Turma do Superior Tribunal de Justiça, no REsp 1.316.92, entendeu que os provedores de 
busca não podem ser compelidos a controlar resultados, pois são apenas meios de acesso ao conteúdo e não os responsáveis pela publicação. Desse modo, além de não poderem ser responsabilizados pelo conteúdo ilícito disponibilizado na rede, não devem censurar a abrangência da busca nem impedir o acesso de todos à informação.

Em recente decisão proferida pelo Superior Tribunal de Justiça, no julgamento da Reclamação n ${ }^{\circ}$ 5.072/AC, a referida Corte manteve o posicionamento adotado, inclusive com a transcrição idêntica do acórdão supracitado, entendendo que, no conflito entre o direito à privacidade do usuário lesado e o direito à informação da coletividade, previsto no art. $220, \$ 1{ }^{\circ} \mathrm{da} \mathrm{CRFB} / 88$, deveria este último direito fundamental prevalecer. Importa destacar que o STJ utilizou fundamentação idêntica ao julgado anterior quando da ponderação entre o direito ao acesso à informação e à privacidade.

Abstraindo-se do mérito técnico da decisão, no tocante à responsabilização dos provedores de busca, é possível aferir que o Superior Tribunal de Justiça realizou um juízo de merecimento de tutela entre o direito da coletividade ao acesso à informação e o direito à privacidade dos recorrentes, de modo a conferir tutela preferencial àquele.

Todavia, tais decisões merecem críticas à luz da melhor técnica adotada no sopesamento de interesses em colisão. Destaca-se como direito fundamental de extrema importância histórica o direito da coletividade à informação, previsto no art. $220, \$ 1^{\circ}$ da CRFB/88. No entanto, abstratamente, não comporta uma carga valorativa superior aos demais direitos dotados de jusfundamentalidade, assim como não é absoluto.

Embora o contexto histórico vivenciado com o advento do Estado Social tenha fortalecido os mecanismos de tutela dos direitos coletivos, difusos e homogêneos, não há precedência em abstrato dos direitos de titularidade coletiva sobre direitos individuais.

O caso concreto, objeto das decisões em análise, envolve a colisão entre dois interesses legítimos: a pretensão da pessoa lesada em manter a sua privacidade, por ter inúmeros aspectos de sua personalidade expostos ao conhecimento público de modo facilitado pelos padrões de busca com resultados lesivos, e o interesse da coletividade em ter acesso a tais informações.

No sopesamento entre os interesses em conflito, o princípio jurídico da dignidade da pessoa humana deverá guiar o intérprete na identificação daquilo que deve ser merecedor de proteção. Nessa perspectiva, Sarlet (2015, p. 149) destaca a função limitadora dos direitos fundamentais assumida pela dignidade da pessoa humana:

Considerando a perspectiva da dignidade como limite cabe lembrar que, no âmbito da indispensável ponderação (e, por conseguinte, também hierarquização) de valores, que diz com a tarefa de estabelecer a concordância prática (na acepção de Hesse) na hipótese de conflitos entre princípios (e direitos) constitucionalmente assegurados, o princípio da dignidade da pessoa humana acaba por justificar (e até mesmo exigir) a imposição de restrições a outros bens constitucionalmente protegidos, ainda que se cuide de normas de cunho jusfundamental. 
Dessa forma, a precificação das informações dos lesados e sua veiculação de modo a satisfazer a curiosidade pública parecem não condizer com a afirmação da dignidade humana. Os corolários da liberdade, integridade psíquica e solidariedade social (MORAES, 2010) foram conjuntamente violados nas decisões proferidas. A liberdade dos usuários para construir livremente a esfera de sua personalidade no ambiente digital e a integridade psíquica destes, ao terem expostos aspectos da sua vida privada publicamente, estão comprometidas. Bem como, ao facilitar a rememoração de fatos ocorridos no passado, sem qualquer relevância, atualidade e historicidade, cerceando o direito do usuário a se reintegrar socialmente na comunidade e reconstruir a sua personalidade, os provedores também violam o corolário da solidariedade social.

Importa salientar, ainda que o princípio jurídico da dignidade da pessoa humana apresente-se como importante parâmetro para a solução de casos difíceis, não poderá servir como argumento abstrato para a solução de todos os casos, de modo a se afirmandar como um "coringa" das decisões judiciais.

Embora seja qualificada como um valor ou princípio fundamental, a dignidade da pessoa humana não tem caráter absoluto. É certo que ela deverá ter precedência na maior parte das situações em que entre em rota de colisão com outros princípios, mas, em determinados contextos, aspectos especialmente relevantes da dignidade poderão ser sacrificados em prol de outros valores individuais ou sociais, como na pena de prisão, na expulsão do estrangeiro ou na proibição de certas formas de expressão (BARROSO, 2010, p. 15).

Destarte, utilizando-se da técnica de sopesamento de normas constitucionais com estrutura principiológica desenvolvida por Alexy (2008, p. 102), percebe-se a possibilidade de transpor a solução conferida no Caso Lebach, que também envolveu a colisão entre o direito de informar à coletividade e os direitos de personalidades, à análise das decisões em epígrafe. Do sopesamento entre princípios, as condições as quais sejam capazes de preservar os direitos de personalidade do autor devem ter precedência sobre a liberdade de informar.

Por sua vez, a teoria desenvolvida por Dworkin (2010) apresenta a figura imaginária do Juiz Hércules, como um juiz ideal capaz de satisfazer as exigências da integridade para o direito, resolvendo os conflitos interpretativos que exsurgem nas disputas jurídicas e, ao final, estabelecer a melhor resposta para os casos que desafiam sua capacidade jurisdicional, afinal, diante de um caso difícil, apenas uma única resposta se apresenta.

Diante da colisão entre princípios, a dimensão de peso ou importância deve guiar a solução apresentada, pois, diferentemente das regras que se submetem ao modelo do "tudo-ou-nada", o princípio de maior peso se sobreporá ao outro, sem que este perca a sua validade (DWORKIN, 2010, p. 40). Nessa perspectiva, nos casos expostos, o princípio de maior peso ou importância será o que melhor promova a dignidade da pessoa humana.

Portanto, a solução hábil a realizar os valores da ordem jurídica e proteger e promover o princípio jurídico da dignidade da pessoa humana, seria, nos casos em discussão, a que conferisse tutela prioritária ao direito à privacidade, visto como direito à autodeterminação informativa no contexto da sociedade da informação digital. 


\section{CONCLUSÃO}

As fronteiras do direito civil não são estáticas, de modo que a reedificação dessas acompanhou as peculiaridades e os influxos das ideologias dominantes em determinados períodos históricos. Por opção metodológica, fez-se uma análise das mudanças na fisionomia do direito privado, partindo do contexto histórico evidenciado com o surgimento do Estado Moderno e das ideias liberais (Era das Codificações) até a perspectiva Civil-Constitucional, a que melhor foi capaz de solucionar os complexos problemas presentes na Sociedade da Informação.

O modelo oitocentista proposto pela Escola Pandectista Alemã, que elevava a propriedade privada e os contratos ao centro das preocupações do direito civil e adotava a subsunção como técnica de interpretação e aplicação do direito, mostrou-se inadequado diante da complexa realidade histórica, econômica e social vivenciada na contemporaneidade.

Dessa forma, a metodologia do direito civil-constitucional colocou-se à frente do processo de reedificação das fronteiras do direito civil, de modo a deslocar as preocupações com a liberdade individual e o patrimônio para a dimensão solidarista do direito civil, enquanto instrumento de promoção de valores, especialmente os existenciais. Embora alvo de críticas pertinentes ao decisionismo que a adoção de uma hermenêutica civil-constitucional conferiria ao intérprete, percebeu-se que tal desvio pode ser perfeitamente superado pela correta fundamentação jurídica da decisão judicial, embasada nos valores da ordem jurídica unitária.

Os influxos históricos foram decisivos na redefinição das fronteiras da legalidade no direito civil, influenciaram a dogmática metodológica do direito privado e traçaram a evolução das técnicas de interpretaçãoaplicação desse direito. Desta feita, ao longo dessa trajetória, uma questão jurídica sempre caminhou no eixo central das discussões: qual seria a dimensão de controle da autonomia privada.

Evidenciou-se que o juízo valorativo dos atos privados mais hábil a instrumentalizar a solução da colisão de interesses no contexto da sociedade da informação seria o da identificação dos interesses merecedores de tutela, instância positiva de legitimação dos atos conforme os valores do sistema. Ademais, constatou-se que o princípio jurídico da dignidade da pessoa humana impõe-se como eficaz baliza a auxiliar o intérprete na técnica do merecimento de tutela.

Finalmente, da análise crítica das decisões do Superior Tribunal de Justiça, no Resp1.316.92 e na Reclamação no 5.072/AC - situação na qual o STJ aplicou o juízo de merecimento de tutela - optando por proteger preferencialmente o direito da coletividade à informação; percebeu-se que não houve o devido sopesamento entre os interesses colidentes. 
Afinal, a solução mais consentânea aos valores da ordem jurídica e capaz de proteger e promover o princípio jurídico da dignidade da pessoa humana, seria, nos casos em discussão, a que conferisse tutela prioritária ao direito à privacidade, visto como direito à autodeterminação informativa no contexto da sociedade da informação digital.

\title{
DESERVING TRUSTEESHIP IN THE INFORMATION SOCIETY: REBUILDING THE BORDERS OF CIVIL LAW
}

\begin{abstract}
The right to privacy, in its dynamic aspect, as a right to informational self-determination, will come into collision with the right of access to information, when it should be promoted an evaluative judgment in order to gauge the interest worthy of protection. The civil and constitutional rights have been presenting itself as a rebuilding instrument the boundaries of civil law, strengthening the protection of existential values, this way, the judgment of guardianship worthiness arises as a positive instance of legitimization of private acts in the light of the unitary legal order values. The methodology used is bibliographical, case law, pure, descriptive and exploratory. It was concluded that the correct application of the merit judgment of guardianship, when the collision between the right to privacy and the right to information, in this case, grant preferential protection of the right to informational selfdetermination, to better achieve the values in legal system as a whole, while it is consistent to the protection of the legal principle of human dignity.
\end{abstract}

Keywords: Information Society. Civil right. Deserving Trusteeship. Rigth to informational self-determination. Rigth to privacy.

\section{REFERENCIAS}

ANDRADE, José Carlos Vieira de. Os direitos fundamentais na Constituição Portuguesa de 1976. 2 ed, Coimbra: Almedina, 2001.

ALEXY, Robert. Teoria dos direitos fundamentais. Tradução Virgílio Afonso da Silva. São Paulo: Malheiros, 2008.

BAUMAN, Zygmunt. Privacidade, sigilo, intimidade, vínculos humanos- e outras baixas colaterais da modernidade líquida. In Danos colaterais: desigualdades sociais numa era global. Tradução de Carlos Alberto Medeiros. Rio de Janeiro: Zahar, 2013.

BARROSO, Luís Roberto. A dignidade da pessoa humana no direito constitucional contemporâneo. São Paulo: Fórum, 2012.

A Dignidade da Pessoa Humana no Direito Constitucional Contemporâneo: Natureza Jurídica, Conteúdos Mínimos e Critérios de Aplicação. Versão provisória para debate público. Mimeografado, dezembro de 2010 . 
BOBBIO, Norberto. Teoria generale del diritto. Torino: Giappichelli, 1993.

BRASIL. Constituição (1988). Constituição da República Federativa do Brasil. São Paulo: Saraiva, 2016.

REsp 1.316.921-RJ, Rel. Min. Nancy Andrighi, j. em 26.06.2013. Disponível em:

<http://www.stj.jus.br/webstj/processo/justica/detalhe.asp?numreg=201103079096>. Acesso em: 20 jun. 2016.

Rcl 5.072, Rel. Min, Nancy Andrighi, j. em 11.12.2013. Disponível em:

<http://stj.jusbrasil.com.br/jurisprudencia/25138018/reclamacao-rcl-5072-ac-2010-0218306-6-stj/inteiroteor-25138019>. Acesso em: 20 jul. 2016.

CASTELLS, Manuel. A sociedade em rede. Tradução de Roneide Venâncio Majer. 8. ed. rev. ampl. São Paulo: Paz e Terra, 2005.

CALCINI, Fábio Pallareti. Abuso de direito e o novo Código Civil, São Paulo: Revista dos Tribunais, 2004.

DENNINGER, Erhard. Racionalidad tecnológica, responsabilidad ética y derecho post moderno. Doxa, n. 14, 1993.

DOMAT, Jean. Le leggi civili nel loro ordine naturale, 7v. Trad. it. A. Padovani. Pavia: Tip. Bizzoni, 1825.

DWORKIN, Ronald. Levando os direitos a sério. 3. ed. São Paulo: WMF Martins Fontes, 2010.

GODINHO, Adriano Marteleto. O fenômeno da constitucionalização: um olhar sobre o direito civil. Disponível em: <http://www.institutodcc.com.br/news/o-fenomeno-da-constitucionalizacao-um-novo-olhar-sobre-odireito-civil $>$. Acesso em: 15 jul. 2016.

GIORGIANNI, Michele. O direito privado e suas atuais fronteiras. Revista dos Tribunais, São Paulo, n. 747, 1998 [1961].

HABERMAS, Jürgen. L' idée d'État de droit. In: Droit et morale: Tanner Lectures. Paris: Seuil, 1997 [1986].

IRTI, Natalino. L'età della decodificazione. Revista de Direito Civil, Imobiliário, Agrário e Empresarial, n. 10. Rio de Janeiro, out.-dez., 1979.

JOSSERAND, Louis. De L'sprit des droits et leur relativitè. Paris: Dalloz, 1927.

KANT, Immanuel. Princípios metafísicos del derecho. Tradução G. Lizarrga. Madrid: Librería de Victoriano Suarez, 2007.

LARENZ, Karl. Metodologia da ciência do direito. Lisboa: Caloustte Gulbenkian, 2012.

LOPES, Serpa. Curso de direito civil, v. I. 2. ed. São Paulo: Freitas Bastos, 1955.

MORAES, Maria Celina Bodin de. Na medida da pessoa humana: estudos de direito civil. Rio de Janeiro: Renovar, 2010

NEGROPONTE, Nicholas. A vida digital. Tradução: Sérgio Tellaroli. São Paulo: Companhia das Letras, 1995. 
ORWELL, George. 1984. Tradução de Wilson Velloso. Companhia Editorial Nacional: São Paulo. Disponível em: <http://about-brazil.org/books/1984.pdf>Acesso em: 29 jul. 2016.

PERLINGIERI, Pietro. O direito civil na legalidade constitucional. Rio de Janeiro: Renovar, 2008.

Perfis do direito civil: uma introdução ao direito civil constitucional. Rio de Janeiro, RJ: Renovar, 2007.

RODOTÀ, Stefano. A vida na sociedade da vigilância: a privacidade hoje. Organização, seleção e apresentação de Maria Celina Bodin de Moraes. Tradução: Danilo Doneda e Luciana Cabral Doneda. Rio de Janeiro: Renovar, 2008.

RODRIGUES, Francisco Luciano Lima. O fenômeno da constitucionalização do direito: seus efeitos sobre o direito civil. In: Direito Civil Constitucional: a ressignificação da função dos institutos fundamentais do Direito Civil Contemporâneo e suas consequências. Orgs. Carlos Eduardo Pianovski Ruzyk; Joyceane Bezerra de Menezes; Florianópolis: Conceito, 2014.

SARLET, Ingo Wolfgang. Dignidade (da pessoa) humana e direitos fundamentais na Constituição Federal de 1988. 10 ed. rev. atual. e ampl. Porto Alegre: Livraria do Advogado, 2015.

SOUZA, Eduardo Nunes de. Merecimento de tutela: a nova fronteira da legalidade no direito civil. Revista de Direito Privado. Nelson Nery Jr.; Rosa Maria de Andrade Nery (coord.). São Paulo: Revista dos Tribunais, abr.jun., 2014.

STRECK, Lênio. Hermenêutica. Constituição e autonomia do direito. Revista de Estudos Constitucionais, Hermenêutica e Teoria do Direito. jan-jun., 2009.

TEPEDINO, Gustavo. O Código Civil, os chamados microssitemas e Constituição: premissas para uma reforma legislativa. In: Problemas de direito civil. Gustavo Tepedino (coord.). Rio de Janeiro: Renovar, 2001.

WARREN, Samuel Dennis; BRANDEIS, Louis Dembitz. The right to privacy. Harvard: Law Review. 1890.

WIEACKER, Franz. História do Direito Privado Moderno. 4 ed, Lisboa: Fundação CaloustreGulbenkian, 2010.

WIENER, Norbert. Cibernética e Sociedade - o uso humano de seres humanos. 4ed. São Paulo: Cultrix, 1973.

Trabalho enviado em 20 de junho de 2016.

Aceito em 06 de outubro de 2016. 